Research Journal of Agronomy 4 (3): 63-69, 2010

ISSN: $1815-9354$

(C) Medwell Journals, 2010

\title{
Effects of Salinity on Seedling Biomass Production and Relative Water Content of Some Haricot Bean (Phaseolus vulgaris) Varieties
}

\author{
Kinfemichael Geressu Asfaw \\ ${ }^{1}$ Department of Biology, College of Natural and Computational Sciences (CNCS), \\ Mekelle University (MU), P.O. Box 3112, Ethiopia
}

\begin{abstract}
The aim of this research was to study the effects of salinity on 14 haricot bean (Phaseolus vulgaris) varieties at $0,2,4,8$ and $16 \mathrm{dS} \mathrm{m}^{-1}$. Data analysis was carried out using jmp 5 (version 5.0) and SPSS (version 12) statistical softwares. Seedling Shoot Fresh Weight (SSFW), Seedling Shoot Dry Weight (SSDW), Seedling Root Fresh Weight (SRFW) and Seedling Root Dry Weight (SRDW) were measured and seedling Shoot Relative Water Content (SRWC) and seedling Root Relative Water Content (RRWC) were calculated. The two ways ANOVA for varieties found statistically insignificant with respect to Seedling Root Fresh Weight (SRFW), seedling Shoot Relative Water Content (SRWC) and seedling Root Relative Water Content (RRWC) ( $>$ >0.05) but it was significant with respect to Seedling Shoot Fresh Weight (SSFW), Seedling Shoot Dry Weight (SSDW) and Seedling Root Dry Weight (SRDW) $(\mathrm{p}<0.05)$. On the other hand, the two ways ANOVA for treatments displayed statistical significance for all the above parameters at $(\mathrm{p}<0.0001)$. However, it was insignificant for variety treatment interaction $(\mathrm{p}>0.05)$ with respect to the entire parameters. Varieties such as Awash-1, Argene, Chore, Mexican 142 and Awash Melka were found to be salt tolerant during seedling biomass production and in Relative Water Content (RWC). On the other hand, varieties Red Kidney (DRK), Dimtu, Gofta, Cranscope and Sinkinesh were found to be salt sensitive during seedling biomass production and in RWC. The rest haricot bean varieties were intermediate in their salt tolerance. The study affirmed the presence of broad intraspecific genetic variation in haricot bean varieties for salt stress with respect to their early biomass production and Relative Water Content (RWC).
\end{abstract}

$\underline{\text { Key words: Dry matter, haricot bean, relative water content, salinity, varieties, biomass }}$

\section{INTRODUCTION}

Salt-affected soils are distributed throughout the world and no continent is free from the problem (Brady and Weil, 2002). Salinization of soil is one of the major factors limiting crop production particularly in arid and semi-arid regions of the world (Ahmed, 2009). Globally, a total land area of 831 million ha is salt affected. African countries like Kenya (8.2 Mha), Nigeria (5.6 Mha), Sudan (4.8 Mha), Tunisia (1.8 Mha), Tanzania (1.7 Mha) and Ghana (0.79) are salt affected to various degrees (FAO, 2000). Salt stress is known to perturb a multitude of physiological processes (Noreen and Ashraf, 2008). It exerts its undesirable effects through osmotic inhibition and ionic toxicity (Munns et al., 2006). Increased salinity caused a significant reduction in germination percentage, germination rate and root and shoots length and fresh root and shoots weights (Jamil and Lee, 2006).

In Ethiopia, salt-affected soils are prevalent in the Rift valley and the lowlands. The Awash valley in general and the lower plains in particular are dominated by salt affected soils (Gebreselassie, 1993). A significant abandonment of banana plantation and a dramatic spread to the adjacent cotton plantation of Melka Sadi farm was reported (Abegaz, 1995). Moreover, of the 4000 ha irrigated land of the above farm $57 \%$ has been saltaffected (Taddese and Bekele, 1996). Similarly, the occurrence of salinity problem in Melka Werer Research farm was reported (Haider et al., 1988). Another study also depicted that of the entire Abaya State farm, 30\% has already been salt-affected (Tsige et al., 2000).

This problem is expected to be severe in years to come. Because under the prevailing situation of the country; there is a tendency to introduce and implement large-scale irrigation agriculture so as to increase productivity (Mamo et al., 1996). In the absence of efficient ways of irrigation water management, salt-build up is an inevitable problem. To alleviate the problem, we need to look for a solution (Gebre and Georgis, 1988). It can be done either using physical or biological practice (Gupta and Minhas, 1993; Marler and Mickelbart, 1993). Since, environmental management (physical approach) is not economically feasible (El-Khashab et al., 1997), there is a need to concentrate on the biological approach or 
crop management (Ashraf and McNeilly, 1988, Ashraf et al., 2008; Ashraf, 2009). Nevertheless to proceed with this approach, affirming the presence of genetically based variation for salt-tolerance in a particular crop is a prerequisite (Verma and Yadava, 1986; Marler and Mickelbart, 1993; Mahmood et al., 2009). This could be done at different crop growth stages such as crop establishment (germination, emergence and seedling growth). There are reasonably adequate information on the effects of salinity on crops germination and emergence (Maas, 1986). However, there is only a little information on the impacts of salinity on crops biomass production during seedling growth (Katerji et al., 1994).

Therefore, this research attempted to investigate the effect of salinity on fourteen haricot bean (Phaseolus vulgaris) varieties with respect to seedling biomass production and Relative Water Content (RWC).

\section{MATERIALS AND METHODS}

This study was conducted in Ethiopia from March 2008 to April 2009 at Mekelle University in the Laboratory of Biology Department. Seeds of 14 haricot bean (Phaseolus vulgaris) varieties were obtained from Melkassa Agricultural Research Center (MARC). The specific haricot bean varieties used in the research were Roba-1, Gofta, Chore, Awash-1, Awash Melka, Sinkinesh, Dimtu, Red Kidney (DRK), Tabor, Nassier, Zebra, Cranscope, Mexican 142 and Argene. Moreover, the $\mathrm{NaCl}$ concentrations used were $2,4,8$ and $16 \mathrm{dS} \mathrm{m}^{-1}$. These salinity levels were obtained by dissolving $1.12,2.10,4.95$ and $9.9 \mathrm{~g} \mathrm{NaCl}$ in $1 \mathrm{~L}$ of distilled water, respectively. Distilled water $\left(0 \mathrm{dS} \mathrm{m}^{-1}\right)$ was served as a control.

Germination experiment was conducted in a laboratory at room temperature using the procedures followed by Verma and Yadava (1986) and Mamo et al. (1996). Petri dishes with a diameter of $10 \mathrm{~cm}$ that have been lined with whatman no. 3 filter study were supplied with $10 \mathrm{~mL}$ of each treatment solution (4 treatment solutions and the control). Following this, 8 uniform seeds of haricot bean varieties were placed on each petri dish and the petri dishes were arranged in a Randomized Complete Block Design (RCBD) with 4 replications. Eventually, the petri dishes were covered with a polyethylene sheet to avoid the loss of moisture through evaporation. Treatment application continued every other day and germination count was started after $48 \mathrm{~h}$ of sowing and continued until the 14 th day. The seed was considered to have germinated when both the plumule and radicle had emerged $\geq 0.5 \mathrm{~cm}$. After the 14 days, seedling shoot and root fresh weights were recorded and finally oven dried at $70^{\circ} \mathrm{C}$ for $48 \mathrm{~h}$ and the seedling shoot and root dry weight were measured using sensitive balance. Relative seedling water content was calculated: fresh weight-dry weight/fresh weight $\times 100$ (Shalaby et al.,1993).

\section{RESULTS AND DISCUSSION}

Seedling Shoot Fresh Weight (SSFW): The two ways ANOVA for variety $(p<0.05)$ and treatment $(p<0.0001)$ was significant. However, it was statistically insignificant for variety treatment interaction $(\mathrm{p}>0.05)$ with regard to Seedling Shoot Fresh Weight (SSFW). Seedling Shoot Fresh Weight (SSFW) was facilitated at $2 \mathrm{dS} \mathrm{m}^{-1}$ in all varieties and also at both 2 and $4 \mathrm{dS} \mathrm{m}^{-1}$ in varieties Awash-1, Chore, Dimtu, Red Kidney (DRK), Gofta, Nassier, Roba-1, Awash Melka and Zebra as compared to the control. Varieties Red Kidney (DRK), Gofta, Cranscope and Dimtu were more salt-affected but varieties Awash-1, Argene, Chore, Awash Melka and Mexican 142 were least salt-affected at both 8 and $16 \mathrm{dS} \mathrm{m}^{-1}$ salt concentrations (Fig. 1).

Seedling Root Fresh Weight (SRFW): The two ways ANOVA for variety treatment interaction and variety was insignificant $(p>0.05)$ however, it was significant for treatment $(\mathrm{p}<0.001)$ with respect to Seedling Root Fresh Weight (SRFW). Seedling Root Fresh Weight (SRFW) was enhanced at $2 \mathrm{dS} \mathrm{m}^{-1}$ in varieties Awash-1, Chore, Nassier, Cranscope and Roba-1 and also at both 2 and $4 \mathrm{dS} \mathrm{m}^{-1}$ in variety Gofta as compared to the control. Varieties Dimtu, Red Kidney (DRK), Cranscope and Sinkinesh were most salt-affected but varieties Awash-1, Argene, Chore, Mexican 142 and Awash Melka were found to be least salt-affected at 8 and $16 \mathrm{dS} \mathrm{m}^{-1}$ salinity levels (Fig. 2).

Seedling Shoot Dry Weight (SSDW): The two ways ANOVA showed statistical significance for treatment and variety $(p<0.05)$ but it was insignificant for variety treatment interaction ( $p>0.05$ ) with regard to Seedling Shoot Dry Weight (SSDW). Seedling Shoot Dry Weight (SSDW) was enhanced in all varieties at $2 \mathrm{dS} \mathrm{m}^{-1}$ as compared to the control. Varieties Dimtu, Red Kidney (DRK), Cranscope and Gofta were the most salt-affected however, varieties Awash-1, Argene, Chore, Mexican 142 and Awash Melka were least salt-affected at 8 and $16 \mathrm{dS} \mathrm{m}^{-1}$ salinity levels.

Seedling Root Dry Weight (SRDW): The 2 ways ANOVA for variety treatment interaction was found statistically insignificant $(\mathrm{p}>0.05)$. However, it was significant for variety $(\mathrm{p}<0.05)$ and for treatment 
Res. J. Agron., 4 (3): 63-69, 2010

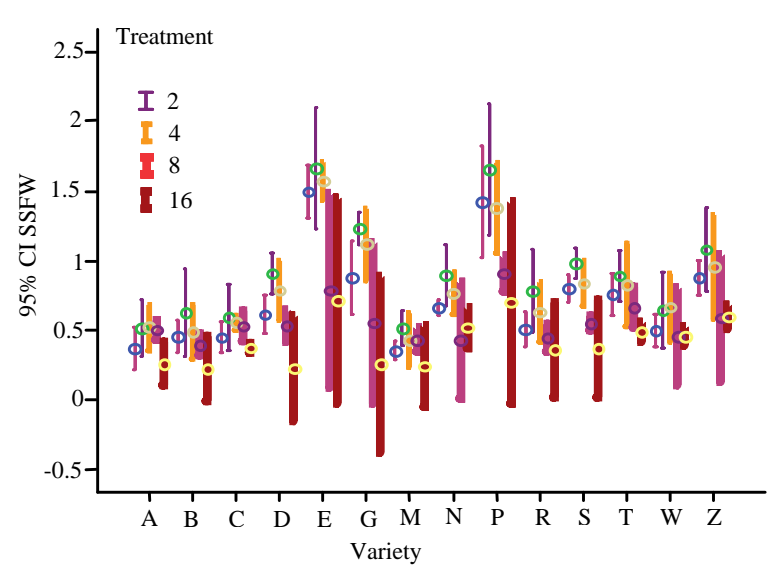

Fig. 1: Effects of different salinity levels $(0,2,4,8$ and $16 \mathrm{dS} \mathrm{m}^{-1}$ ) on Seedling Shoot Fresh Weigth (SSFW) of Phaselolus vulgaris varieties. (Key to Varieties: $\mathrm{R}=$ Roba-1, $\mathrm{G}=$ Gofta, $\mathrm{C}=$ Chore, $\mathrm{A}=$ Awash-1, $\mathrm{W}=$ Awash Melka, $\mathrm{S}=$ Sinkinesh, $\mathrm{D}=$ Dimtu, $\mathrm{E}=$ Red Kidney (DRK), $\mathrm{T}=$ Tabor, $\mathrm{N}=$ Nassier, $\mathrm{Z}=$ Zebra, $\mathrm{P}=$ Cranscope, $\mathrm{M}=$ Mexican 142 and $\mathrm{B}=$ Argene)

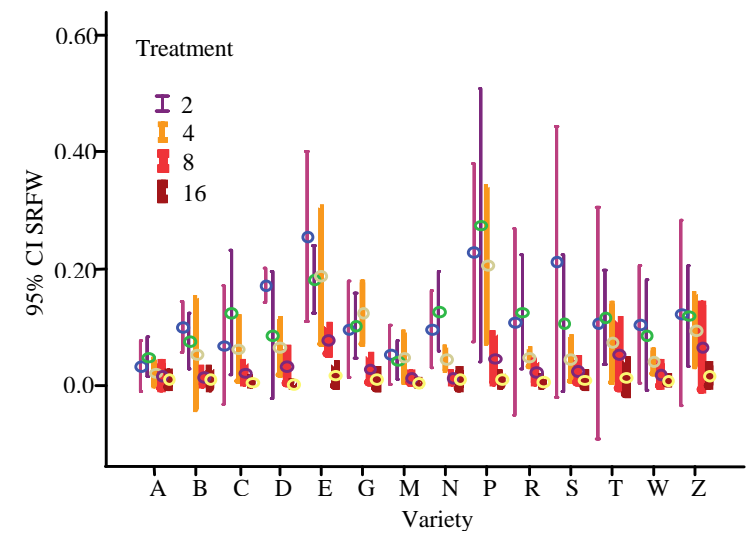

Fig. 2: Effects of different salinity levels $(0,2,4,8$ and $16 \mathrm{dS} \mathrm{m}^{-1}$ ) on Seedling Root Fresh Weight (SRFW) of Phaselolus vulgaris varieties (in centimeter). (Key to Varieties: $\mathrm{R}$ = Roba-1, $\mathrm{G}=$ Gofta, $\mathrm{C}=$ Chore, $\mathrm{A}=$ Awash-1, $\mathrm{W}=$ Awash Melka, $\mathrm{S}=$ Sinkinesh, $\mathrm{D}=$ Dimtu, $\mathrm{E}=$ Red Kidney (DRK), $\mathrm{T}=$ Tabor, $\mathrm{N}=$ Nassier, $\mathrm{Z}=$ Zebra, $\mathrm{P}=$ Cranscope, $\mathrm{M}=$ Mexican 142 and $\mathrm{B}=$ Argene)

( $<<0.0001$ ) with respect to Seedling Root Dry Weight (SRDW). As compared to the control, Seedling Root Dry Weight (SRDW) was enhanced at $2 \mathrm{dS} \mathrm{m}^{-1}$ in varieties Awash-1, Dimtu, Red Kidney (DRK), Gofta, Mexican 142, Nassier, Cranscope, Roba-1 and Tabor. It was also stimulated at $4 \mathrm{dS} \mathrm{m}^{-1}$ in varieties Red Kidney (DRK) and

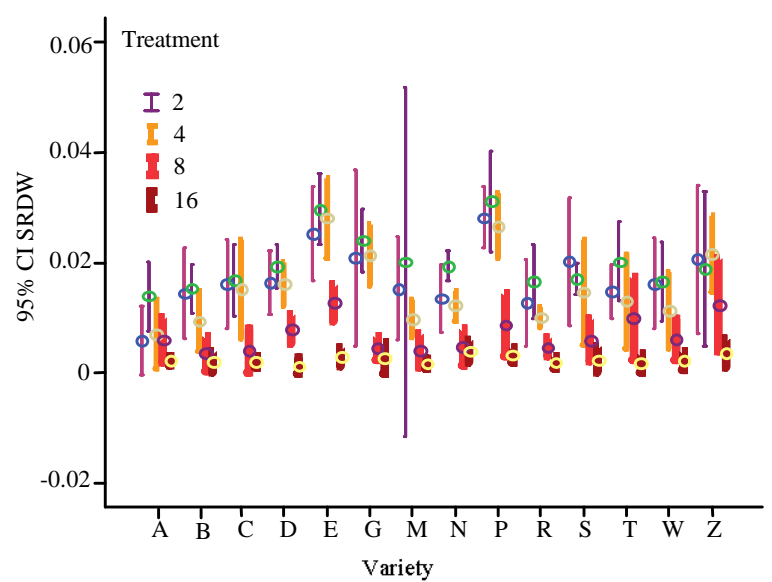

Fig. 3: Effects of different salinity levels $(0,2,4,8$ and 16 $\mathrm{dS} \mathrm{m}^{-1}$ ) on Seedling Root Dry Weigth (SRDW) of Phaselolus vulgaris varieties. (Key to Varieties: $\mathrm{R}=$ Roba- $1, \mathrm{G}=$ Gofta, $\mathrm{C}=$ Chore, $\mathrm{A}=$ Awash-1, $\mathrm{W}$ = Awash Melka, $\mathrm{S}=$ Sinkinesh, $\mathrm{D}=$ Dimtu, $\mathrm{E}=$ Red Kidney (DRK), $\mathrm{T}=$ Tabor, $\mathrm{N}=$ Nassier, $\mathrm{Z}=$ Zebra, $\mathrm{P}=$ Cranscope, $\mathrm{M}=$ Mexican 142 and $\mathrm{B}=$ Argene)

Zebra as compared to the control. At 8 and $16 \mathrm{dS} \mathrm{m}^{-1}$ varieties Dimtu, Red Kidney (DRK), Gofta, Cranscope, Sinkinesh and Zebra were more salt affected however, varieties Awash-1, Argene, Mexican 142, Nassier and Roba-1 were least salt-affected (Fig. 3).

Seedling Shoots Relative Water Content (SRWC): The two ways ANOVA showed statistical significance for treatment $(p<0.0001)$. However, it was insignificant for both variety and variety treatment interaction $(\mathrm{p}>0.05)$ with regard to Seedling Shoots Relative Water Content (SRWC). Seedling Shoot Relative Water Content (SRWC) was facilitated in all varieties as compared to the control. Moreover, it was stimulated both at 2 and $4 \mathrm{dS} \mathrm{m}^{-1}$ in varieties Awash-1, Chore, Dimtu, Red Kidney (DRK), Gofta, Nassier, Cranscope, Roba-1, Tabor, Awash Melka and Zebra. Varieties Red Kidney (DRK), Gofta, Cranscope, Sinkinesh and Zebra had the lowest SRWC and but varieties Awash-1, Argene, Chore, Mexican 142 and Awash Melka possessed the highest Shoot Relative Water Content (SRWC) (Fig. 4).

Seedling Roots Relative Water Content (RRWC): The 2 way ANOVA for treatments was statistically significant $(\mathrm{p}<0.0001)$ but it was insignificant for variety and variety treatment interaction $(\mathrm{p}>0.05)$ with respect to seedling Root Relative Water Content (RRWC). seedling Root Relative Water Content (RRWC) was stimulated at $2 \mathrm{dS} \mathrm{m}^{-1}$ in varieties Chore, Nassier, Cranscope, Roba-1 
Res. J. Agron., 4 (3): 63-69, 2010

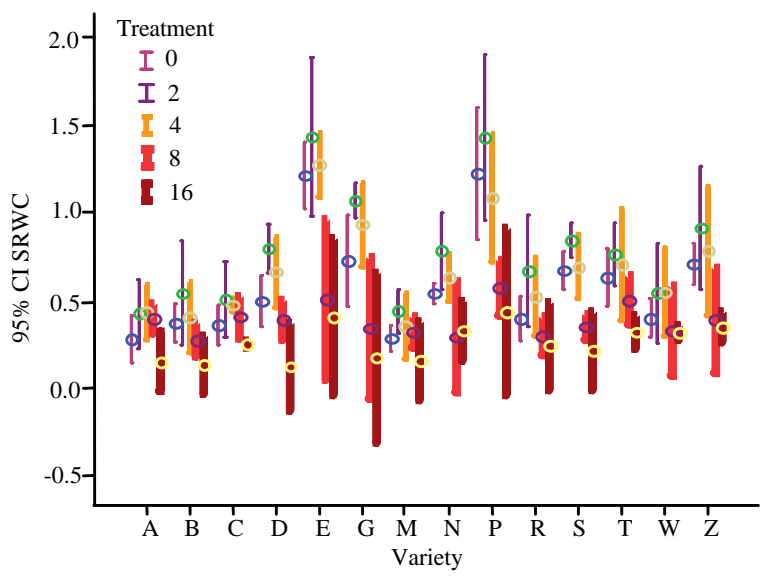

Fig. 4: Effects of different salinity levels $(0,2,4,8$ and $16 \mathrm{dS} \mathrm{m}^{-1}$ ) on Seedling Shoot Relative Water Content (SRWC) of Phaselolus vulgaris varieties (Key to Varieties: $\mathrm{R}=$ Roba- $1, \mathrm{G}=$ Gofta, $\mathrm{C}=$ Chore, $\mathrm{A}=$ Awash-1, $\mathrm{W}=$ Awash Melka, $\mathrm{S}=$ Sinkinesh, $\mathrm{D}=$ Dimtu, $\mathrm{E}=$ Red Kidney (DRK), $\mathrm{T}=$ Tabor, $\mathrm{N}=$ Nassier, $\mathrm{Z}=$ Zebra, $\mathrm{P}=$ Cranscope, $\mathrm{M}=$ Mexican 142 and $\mathrm{B}=$ Argene)

and Awash-1 and both at 2 and $4 \mathrm{dS} \mathrm{m}^{-1}$ in variety Gofta as compared to the control. Varieties Dimtu, Red Kidney (DRK), Cranscope and Sinkinesh had the least seedling Root Relative Water Content (RRWC). However, varieties such as Awash-1, Chore, Gofta, Mexican 142, Nassier and Awash Melka had the highest seedling Root Relative Water Content (RRWC). The remaining varieties had intermediate seedling Root Relative Water Content (RRWC) (Fig. 5).

In varieties Dimtu, Red Kidney (DRK), Gofta, Cranscope, Sinkinesh, Tabor and Zebra Seedling Shoot Fresh Weight (SSFW) decreased as the salinity level increased. This does agree with previous studies conducted in durum wheat and tef (Mamo et al., 1996) and phaseolus species (Bayuelo-Jimenez et al., 2002). Increased salinity level caused simultaneous reduction of seedling shoot and root fresh weights in varieties Red Kidney (DRK), Dimtu and Cranscope. This is in line with previous reports in wheat (Afzal et al., 2005) and sugar beat, cabbage, amaranth and pak-choi (Jamil and Lee, 2006).

In general, Seedling Shoot Fresh Weight (SSFW) was more salt affected than Seedling Root Fresh Weight (SRFW). This is in accord with previous research reports in wheat and triticale genotypes (Shalaby et al., 1993), phaseolus species (Bayuelo-Jimenez et al., 2002) and sugar beat, cabbage, amaranth and pak-choi (Jamil and Lee, 2006). Increased salinity level caused simultaneous reduction in seedling root and shoot dry matter

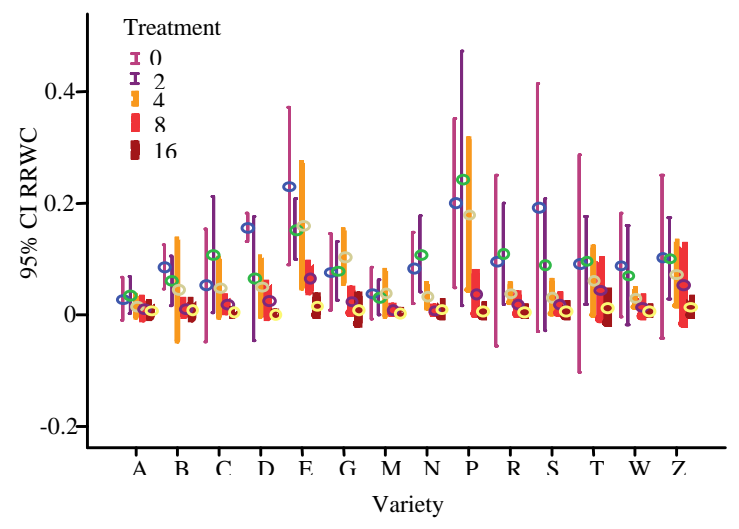

Fig. 5: Effects of different salinity levels $(0,2,4,8$ and $16 \mathrm{dS} \mathrm{m}^{-1}$ ) on Seedling Root Relative Water Content (RRWC) of Phaselolus vulgaris varieties (Key to Varieties: $\mathrm{R}=$ Roba-1, $\mathrm{G}=$ Gofta, $\mathrm{C}=$ Chore, $\mathrm{A}=$ Awash-1, $\mathrm{W}=$ Awash Melka, $\mathrm{S}=$ Sinkinesh, $\mathrm{D}=$ Dimtu, $\mathrm{E}=$ Red Kidney (DRK), $\mathrm{T}=$ Tabor, $\mathrm{N}=$ Nassier, $\mathrm{Z}=$ Zebra, $\mathrm{P}=$ Cranscope, $\mathrm{M}=$ Mexican 142 and $\mathrm{B}=$ Argene)

production (SSDW and SRDW) in varieties Dimtu, Red Kidney (DRK), Cranscope and Gofta. Similar, research results were reported in sorghum (Boursier and Lauchli, 1990), wheat and triticale genotypes (Shalaby et al., 1993), barely (Cho and Kim, 1998) and prosopis alba (Meloni et al., 2004). On the other hand, both seedling fresh and dry biomass production (SSFW, SRFW, SSDW and SRDW) were concurrently reduced as a result of increased salinity level in varieties Gofta, Cranscope and Red Kidney (DRK). This does agree with previous research findings in rice (Shannon et al., 1998), Phaseolus species (Bayuelo-Jimenez et al., 2002), wheat (Afzal et al., 2005) and catharanthus roseus (Abdul-Jaleel et al., 2008). Seedling Relative Water Content (RWC) was drastically decreased at higher salinity level, $16 \mathrm{dS} \mathrm{m}^{-1}$. However, the impact was remarkable on Shoot Relative Water Content (SRWC) compared to the Root Relative Water Content (RRWC). This is in agreement with previous reports in lentil (Ashraf and Waheed, 1993), Maize (Cicek and Cakirlar, 2002), Prosopis alba (Meloni et al., 2004).

The two ways ANOVA for treatments was significant with regard to all parameters considered. On the one hand, the ANOVA for varieties was insignificant with respect to SRFW, RRWC and SRWC. This implies that there were no significant varietal differences among haricot bean varieties in relation to the parameters considered above. However, it was significant with respect to SSFW, SSDW and SRDW. This reveals the presence of considerable 
varietal differences among haricot bean varieties in respect to SSFW, SSDW and SRDW. Accession treatment interaction was insignificant for Seedling Shoot Fresh Weight (SSFW), Seedling Shoot Dry Weight (SSDW), Seedling Root Fresh Weight (SRFW), Seedling Root Dry Weight (SRDW) and seedling Root Relative Water Content (RRWC) and seedling Shoot Relative Water Content (SRWC); reflecting that all accessions responded similarly to salt stress with respect to these parameters. In general, salt stress at $2 \mathrm{dS} \mathrm{m}^{-1}$ stimulated SSFW, SRFW, SSDW, SRDW, RRWC and SRWC in some varieties. The impact of 2 and $4 \mathrm{dS} \mathrm{m}^{-1}$ salinity levels was not profound with respect to all parameters considered. Nevertheless, most varieties were profoundly affected at 8 and $16 \mathrm{dS} \mathrm{m}^{-1}$ salinity levels.

Crop cultivar may germinate effectively under salt stress; nevertheless, its seedling growth may be salt-affected (Azhar and McNeilly, 1987).

In line with this, varieties Roba-1, Red Kidney (DRK), Tabor and Zebra were less salt-affected during germination (in another study) than subsequent growth (had inadequate seedling biomass production and relative water content).

This implies that these accessions are salt tolerant during germination than subsequent growth like seedling biomass production and relative water content. On the other hand, crop genotype may be salt sensitive during both germination and seedling growth. This has already been reported in rice (Shannon et al., 1998) and cowpea (Murillo-Amador and Troyo-Dieguez, 2000). Similarly in this research, variety Red Kidney (DRK) and Dimtu were found salt sensitive at higher salinity levels during germination and seedling biomass production and through their relative water content.

Thus these haricot bean variety could not be directly cultivated even on slightly saline soils. On the other hand, varieties Awash-1, Argene, Chore, Mexican 142 and Awash Melka were found salt tolerant with respect to seedling biomass production and Relative Water Content (RWC). These accessions also had the lowest germination rate (rapid emergence and facilitated seedling growth) (in another study).

Their salt tolerance capability might emanate from their faster germination which allowed the emerging seedlings to accumulate more biomass relative to the control (Bayuelo-Jimenez et al., 2002). Thus due to the facilitated seedling root and shoot characteristics, these genotypes were enabled to possess the highest seedling Relative Water Content (RWC) which in turn enabled them to tolerate the toxic effects of salts through dilution (Lee and Senadhira, 1998). Since, these 5 haricot bean varieties had rapid emergence, facilitated seedling growth, highest seedling biomass production and Relative Water Content (RWC); they could effectively establish themselves on moderately saline soils.

\section{CONCLUSION}

The study revealed the presence of broad intraspecific variation among haricot bean (Phaseolus vulgaris) varieties in response to salt stress during seedling biomass production and Relative Water Content (RWC). Specifically, the study proved that varieties Awash-1, Argene, Chore, Mexican 142 and Awash Melka were the most salt tolerant of all haricot bean varieties studied. Thus these 5 varieties could be cultivated on slightly saline soils directly. Because, owing to their rapid emergence, facilitated growth, highest biomass production and relative water content they could establish themselves effectively on such soils. However, this could not be a guarantee for them to be salt tolerant in later growth stages. Thus to recommend the cultivation of these 5 haricot bean varieties in the field, there must be further profound greenhouse and field investigation at the whole plant growth level.

\section{ACKNOWLEDGEMENTS}

I would like to express my heartfelt thanks to NORAD II Research Award for its financial assistance. Moreover, he's greatly indebted to Mekelle University (MU), Department of Biology, for providing the laboratory and also Melkasa Agricultural Research Centre (MARC) for supplying all the 14 haricot bean (Phaseolus vulgaris) varieties. Finally, his great gratitude and thanks goes to Ato Hayal Lemma and Ato Getachew Gidey for their genuine technical support during the experiment.

\section{REFERENCES}

Abdul-Jaleel, C.B., R. Sankar, R. Sridharan and R. Panneerselvam, 2008. Soil salinity alters growth, chlorophyll content and secondary metabolite accumulation in Catharanthus roseus. Turk. J. Biol., 32: $79-83$.

Abegaz, F., 1995. Effects of subsurface drainage system on ground water table, soil salinity and crop yield in Melka Sadi pilot draiange scheme. Proceedings of the First and Inaugural Conference of the Agronomy and Crop Physiology of Ethiopia, May 30-31, Addis Ababa, Ethiopia, pp: 139-148.

Afzal, I., S. Maqsood, A. Basra, N. Ahmad and M. Farooq, 2005. Optimization of hormonal priming techniques for alleviation of salinity stress in wheat (Triticum aestivum L.). Caderno Pesquisa serie Biologia, 17: 95-109. 
Ahmed, S., 2009. Effect of soil salinity on the yield and yield components of Mungbean. Pak. J. Bot, 4: 263-268.

Ashraf, M. and A.Waheed, 1993. Resposes of some local/exotic accessions of lentil (Lens culinaris Medic.) to salt stress. J. Agron. Crop Sci., 170: 103-112.

Ashraf, M. and T. McNeilly, 1988. Variability in salt tolerance of nine spring wheat cultivars. J. Agron. Crop Sci., 160: 14-21.

Ashraf, M., 2009. Biotechnological approach of improving plant salt tolerance using antioxidants as markers. Biotechnol. Adv., 27: 84-93.

Ashraf, M.J., H.R. Athar, P.J.C. Harris and T.R. Kwon, 2008. Some prospective strategies for improving crop salt tolerance. Adv. Agron., 97: 45-110.

Azhar, M.F. and T. McNeilly, 1987. Variability for salt tolerance in Sorghumn bicolor (L.) Moench. under hydroponic conditions. J. Agro. Crop Sci., 159: $269-277$.

Bayuelo-Jimenez, J.S., R. Graig and J.P. Lynch, 2002. Salinity tolerance of Phaseolus species during germination and early seedling growth. Crop Sci., 42: 1584-1594.

Boursier, P. and A. Lauchli, 1990. Growth responses and mineral nutrient relations of salt-stressed sorghum. Crop Sci., 30: 1226-1233.

Brady, N.C. and R.R. Weil, 2002. The Nature and Properties of Soils. 13th Edn., Prentice Hall, New Jersey, ISBN: 0130167630.

Cho, J.W. and C.S. Kim, 1998. Effect of $\mathrm{NaCl}$ concentration on photosynthesis and mineral content of barely seedlings under solution culture. Korean J. Crop Sci., 43: 152-156.

Cicek, N. and H. Cakirlar, 2002. The effect of salinity on some physiological parameters in two maize cultivars. BULG. J. Plant Physiol., 28: 66-74.

El-Khashab, A.A.M., A.A. Elaidy, A.F. El-Sammak, M.I. Salama and M. Rienger, 1997. Paclobutrazol reduces some negative effects of salt stress in peach. J. Am. Soc. Hort. Sci., 122: 43-46.

$\mathrm{FAO}, 2000$. Land and Plant Nutrition Management Service: Global Network on Integrated Soil Management for Sustainable use of Salt-Affected Soils. FAO/AGL, Rome.

Gebre, H. and K. Georgis, 1988. Sustaining crop production in the semi-arid areas of Ethiopia. Eth. J. Agric. Sci., 10: 99-107.

Gebreselassie, T., 1993. Degradation problems of irrigated agriculture: A review. Proceedings of the Second Conference of ESSS, Sept. 23-24, Addis Ababa, Ethiopia, pp: 199-206.
Gupta, R. and P.S. Minhas, 1993. Managing Salt Affected Waters for Crop Production. In: Arid Land Irrigation and Ecological Management, Singh, S.D. (Ed.). Scientific Publishers, Jodhpur New Delhi, India, pp: 159-198.

Haider, G., G. Desta, T. Hordofa and E. Bekele, 1988. Soil Salinity and Ground Water Survey of Melka Werer Research Center Farm. Institute of Agriculture Research, Melka Werer Research Center, Ethiopia, pp: 42.

Jamil, M. and D. Lee, 2006. Effect of salt ( $\mathrm{NaCl})$ stress on germination and early seedling growth of four vegetables species. Central Eur. Agric. J., 7: 273-283.

Katerji, N., J.W. Von Hoorn, A. Hamdy, F. Karam and M. Mastrorilli, 1994. Effect of salinity on emergence and on water stress and early seedling growth of sunflower and maize. Agric. Water Manage., 26: 81-91.

Lee, S.Y. and D. Senadhira, 1998. Salinity tolerance of progenies between Korean cultivars and IRR's new plant type lines in rice. Korena J. Crop Sci., 43: $234-238$.

Maas, E.V., 1986. Salt tolerance of plants. Applied Agric. Res., 1: 12-26.

Mahmood, A., T. Latif and A.M. Khan, 2009. Effect of salinity on growth, yield and yield components in Basmati rice germplasm. Pak. J. Bot., 41: 3035-3045.

Mamo, T., C. Richter and B. Heiligatag, 1996. Response of some varieties of durum wheat and tef to salt stress. J. Afr. Crop Sci., 4: 423-432.

Marler, T.E. and M.V. Mickelbart, 1993. Growth and chlorophyll fluorescence of Spondias purpurea L. as influenced by salinity. Tropical Agric., 70: 245-247.

Meloni, D.A., M.R. Gulotta, C.A. Martinez and M.A. Oliva, 2004. The effect of salt stress on growth, nitrate reduction and proline and glycinebetaine accumulation in prosopis alba. Braz. J. Plant Physiol., 16: 39-46.

Munns, R., R.A. James and A. Lauchli, 2006. Approaches to increasing the salt tolerance of wheat and other cereals. J. Exp. Bot., 57: 1025-1043.

Murillo-Amador, B. and E. Troyo-Dieguez, 2000. Effects of salinity on the germination and seedling characteristics of cowpea [Vigna unguiculata (L.) Walp.]. Aust. J. Exp. Agric., 40: 433-438.

Noreen, S. and M. Ashraf, 2008. Alleviation of adverse effects of salt stress on sunflower (Helianthus annus L.) by exogenous application of salicylic acid: Growth and photosynthesis. Pak. J. Bot., 40: 1657-1663.

Shalaby, E.E., E. Epstein and C.O. Qualset, 1993. Variation in salt tolerance among some wheat and triticale genotypes. J. Agron. Crop Sci., 171: 298-304. 
Shannon, M.C., J.D. Rhoades, J.H. Draper, S.C. Scardaci and M.D. Spyres, 1998. Assessment of salt tolerance in rice cultivars in response to salinity problems in California. Crop Sci., 38: 394-398.

Taddese, G. and E. Bekele, 1996. Saline and saline-sodic soils of Middle Awash Valley of Ethiopia. Proceedings of the 3rd Conference of ESSS, Feb. 28-29, Ethiopia, pp: 97-110.
Tsige, H., T. Gebresellasie and T. Mamo, 2000. Assessment of salinity/sodicity problems in Abaya State Farm, Southern Rift Valley of Ethiopia. Ethiopian J. Nat. Resour., 2: 151-163.

Verma, S.P.O. and R.B.R. Yadava, 1986. Salt tolerance of some oats (Avena sativa L.) varieties at germination and seedling stage. J. Agron. Crop Sci., 156: $123-127$. 